\title{
HEALTH 2020 - ACHIEVING HEALTH AND DEVELOPMENT IN TODAY'S EUROPE
}

\author{
Zsuzsanna Jakab ${ }^{1}$, Agis D. Tsouros ${ }^{2}$ \\ ${ }^{1}$ WHO Regional Director for Europe, Copenhagen, Denmark \\ ${ }^{2}$ Director, Division of Policy and Governance for Health and Well-being, WHO Regional Office for Europe, Copenhagen, Denmark
}

\begin{abstract}
SUMMARY
The 21st-century health landscape is shaped by growing global, regional and local interdependence and an increasingly complex array of interlinking factors that influence health and well-being. Most of today's major public health challenges, including noncommunicable diseases, antimicrobial resistance, health inequalities and the health effects of austerity measures in some countries, cannot be addressed effectively without intersectoral and coordinated action at supranational, national and local levels. The 53 countries of the WHO European Region developed and adopted a European policy framework and strategy for the 21st century (Health 2020) as a common, evidence-informed policy framework to support and encourage coordinated action by policy-makers at all levels and in all sectors to improve population health and well-being. This article presents the development process of Health 2020 and its main strategic goals, objectives and content. Further, we describe what is needed to successfully implement Health 2020 in countries and how can WHO provide technical assistance to countries that embark on developing health policy aligned with the Health 2020 policy framework.
\end{abstract}

Key words: health policy, regional health planning, public health

Address for correspondence: Agis D. Tsouros, WHO Regional Office for Europe, UN City, Marmorvej 51, DK-2100 Copenhagen, Denmark. E-mail: postmaster@euro.who.int

\section{INTRODUCTION}

Health and well-being are universal human goals that are currently considered to be vital human rights; major components of equitable human, economic and social development; and a resource for everyday life. These goals are increasingly seen as central to human development and security. Health is no longer seen as simply items of consumption to be financed but is considered an asset that needs to be nurtured and equitably improved and also as a positive concept, emphasizing social and personal resources as well as physical capacity.

The lives of all 900 million inhabitants of the 53 countries of the European Region are in focus, and our modern challenge is to make these ideals really influential in a way that improves health equitably across the countries of the WHO European Region. Given what is known, and the technologies available, we can and must do better.

Today health is on the agenda as never before: for example, because of the forces of globalization and the rapid transmissibility of communicable diseases, to mention two factors. Health is a major component of trade, diplomacy and security debates. The health sector is a major economic sector in its own right, a very significant employer and a driver of science, research and technology. The human rights dimensions of health loom large but are often ignored: for example, as concerns about mobility and migration spill over into prejudice and stigma. These are some of the reasons why health matters so much.

People need and expect to influence their health and the determinants of health within their political, social, economic and physical environment. Such influence builds communities and improves health. Then the wide breadth of determinants of health means that health cannot just be the responsibility of the health sector alone, although the sector and health systems can have a very significant role. Collaborative models of working are needed based on shared priorities with other sectors. Action on the determinants of health that represents outcomes for these sectors leads to wider benefits for society, including economic benefits.

The factors underpinning the present-day burden of disease are highly complex and interconnected. Examples include ageing; migration; the predominance of noncommunicable diseases and mental health problems; the remaining challenges from communicable diseases; the performance and financial challenges affecting health systems; and the poor state of development of public health services in many places. Nevertheless, strong evidence indicates that cost-effective policy pathways can be identified to directly enhance population health and well-being through approaches combining government leadership, supportive environments and promoting a sense of control and empowerment. What is needed is a new type of governance for health for the 21 st century based on: the social determinants of health; equity and sustainability; achieving global and societal goals through new interconnected forms of formal and informal governance and new strategic relationships; and built around people's strong voice and involvement. This is both our challenge and our opportunity.

\section{Health 2020}

The 53 countries of the European Region are richly diverse in terms of culture, history, development, wealth, and resources. Despite this diversity, the countries came together at the annual session of the WHO Regional Committee for Europe in September 2012 to approve and commit themselves to implementing 
a new European health policy framework, Health 2020. Health 2020 was supported by an extensive consultation process both within and external to the WHO Regional Office for Europe and several new studies.

A major review of the social determinants of health and the health divide in the WHO European Region was commissioned with the aim of providing evidence-based policy recommendations to reduce inequality in health across the Region and a framework for future action (1). The review has been a two-year project in two phases chaired by Michael Marmot. The full report was published in September 2013. The review analysed the level of health inequities between and within countries within the European Region and reviewed policy options to address these. The review drew on the work of 13 task groups and on the findings and recommendations of the global Commission on Social Determinants of Health: most importantly, that health inequities arise from the conditions in which people are born, grow, live, work and age and the inequities in power, money and resources that give rise to these conditions of daily life. Based on this evidence and analysis, the review provides specific and practical recommendations for policy interventions across the life course and generations that have the potential and capability to reduce health inequalities.

Ilona Kickbusch led major reviews of the principles and implementation of improved governance for health to feed directly into the development of Health 2020 (2). The main study reviewed new approaches to governance that are driven by the changing nature of the challenges of the 21 st century. It was informed by a set of background papers that provide additional in-depth analysis of the issues raised. The study highlights the ongoing diffusion of governance to a collaborative model in which governance is coproduced between a wide range of state (ministries, parliaments, agencies, authorities, commissions etc.), society (businesses, citizens, community groups, global media including networked social media, foundations etc.), and supranational (European Union, United Nations, etc.) actors.

These reviews also informed the governance aspects of the European review of social determinants of health and the health divide.

An analysis of resolutions adopted by the WHO Regional Committee for Europe in the previous 10 years and of World Health Assembly resolutions and declarations at ministerial conferences was issued in September 2012 (3). This review of commitments indicates that Health 2020 may be seen as a reframing of many such commitments within a coherent and visionary approach, overcoming fragmentation and facilitating implementation. However, some issues need more attention now, such as the health of older people, the management of some noncommunicable diseases and the economic implications of health and disease. In addition, the study suggests that the mechanisms and principles underlying the implementation of complex strategies should be better defined and developed. Finally, the study proposes that new resolutions of the WHO Regional Committee for Europe include a brief overview of the progress made on implementing previous commitments.

A review of the experience gained with intersectoral work was published in 2012 (4). This documented experience with health in all policies and assessed the evidence on and compared the effectiveness of various governance structures in producing action on social determinants of health and ultimately on population health outcomes. The publication captures the research showing how intersectoral governance structures can be successfully established, used and sustained. It also provides accessible and relevant examples for policy-makers of the governance tools and instruments available.

Finally, an examination of the economics of disease prevention is about to be published. This will explore the strong developing evidence supporting greater investment in health promotion and disease prevention measures, in terms of cost-effectiveness and outcomes.

The Member States of the WHO European Region approved Health 2020 in two forms. The European policy framework for supporting action across government and society for health and wellbeing (5) provides politicians and key policy practitioners with the main values and principles, as key strategic policy advice for putting Health 2020 into practice. The longer Health 2020 policy framework and strategy (6) provides much more detail in terms of evidence and practice related to health and well-being and is meant for those who practice policy development and implementation at operational levels. The Health 2020 policy framework and strategy is seen as a living guide to policies and strategies, providing links to changes in evidence and practice. It is not a prescription but a practical framework to be used and implemented in the context of each country's circumstances, needs and ambitions.

The background to Health 2020 is the divergent health experience across the WHO European Region. Health has been improving, but inequalities in health remain severe. Fig. 1 shows the quintiles in life expectancy in European countries. The countries differ profoundly, largely along an east-west gradient. Further illustrations are that a child born in the Commonwealth of Independent States is three times as likely to die before the age of five years as a child born in an EU country, and maternal mortality rates are up to 43 times higher in some countries in the Region than others.

Certainly the quality of, and access to, health services differs between these countries. However, all available evidence indicates that these differences substantially reside in different social and economic circumstances. The differences are also linked to health-related behaviour, including tobacco and alcohol use, diet and physical activity and mental disorders, which in turn are socially determined and reflect the stress and disadvantage in people's lives.

Health 2020 was the response to these challenges. Its goal is "to significantly improve the health and well-being of populations, reduce health inequalities, strengthen public health and ensure people-centred health systems that are universal, equitable, sustainable and of high quality". It is based on the values enshrined in the WHO Constitution: the fundamental right of every human being to the highest attainable standard of health, regardless of ethnicity, sex, age, social status, and ability to pay. Also important are the principles of fairness, sustainability, quality, transparency, accountability, the right to participate in decision-making, and dignity.

In summary, the policy framework emphasizes:

- focusing on health and well-being as barometers of development;

- taking a comprehensive approach to the whole spectrum of determinants of health; 


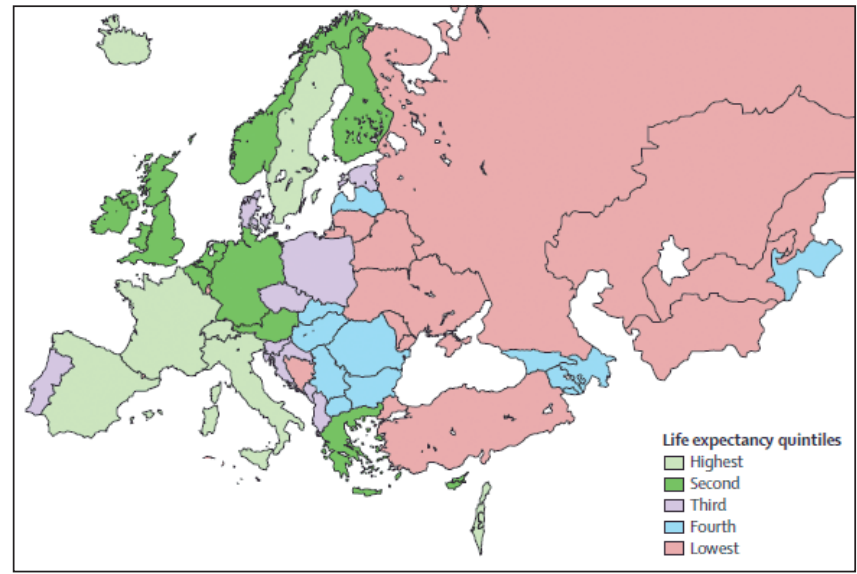

Fig. 1. Life expectancy by quintiles in countries in the WHO European Region, 2010 (or latest available data).

Source: WHO European health for all database.

- addressing the main public health priorities of the Region as well as practical solutions that work;

- taking new and challenging approaches to collaborative leadership to bring many partners together and mobilize broad-based political and cultural support for health development, in order to arrive at joint solutions;

- identifying and responding to the preconditions for change;

- finding ways to make an economic case for investment in health, including evidence on the benefits of, and effective approaches to, health in all policies;

- identifying ways to better facilitate citizen and patient empowerment as key elements for improving health outcomes and the performance of and satisfaction with health systems;

- implementing effective and efficient ways to take advantage of new networking, partnership, communication and technological opportunities;

- implementing a common mechanism in the WHO European Region to build, support and maintain unity and coherence of messaging within the public health community;

- identifying gaps in knowledge and new research priorities; and

- providing an ongoing communication platform for sharing the practical experiences of policy-makers and public health advocates across the Region.

\section{Health 2020's Values and Themes}

Noncommunicable diseases and mental health problems are today's predominant disease burdens, rooted in people's social and economic circumstances and in lifestyles that are themselves socially determined. These diseases result from human interactions with the full range of determinants of health over the life course. Strong evidence emphasizes that fair and equitable access to the opportunities of early childhood development, good education and work and decent housing and income all support health.

Health 2020 makes the case for going upstream to address root causes. Present-day economic studies show not only the economic burden posed by today's diseases but also that these challenges can be met if much greater attention is given to health promotion, disease prevention and public health, in ways that address health inequalities across the social gradient and support the most vulnerable and excluded people. Nevertheless, in many countries today, policies in sectors other than health currently lack either a health or equity focus.

The present situation in most countries is that the share of government budgets spent on health systems is significant, and health care costs have grown faster than national income. Many costs are driven by the supply side, such as new treatments and technologies as well as peoples' increasing expectations for protection from health risks and for high-quality health care interventions. Health systems, like other sectors, need to adapt and change, with such change focusing on primary care and on health promotion and disease prevention, with even more attention given to delivering people-centred and integrated care, for example between primary and secondary care or between providing health care and social care. Reviews of the decline in coronary mortality in several high-income countries show that more than half the decline is attributable to declines in population levels of risk factors such as smoking. Most of the rest of the decline is attributable to efforts in clinical prevention, and the proportion attributed to these appears to be increasing. These reviews strongly justify a combined approach to reducing population risk levels and to providing good clinical management of people with existing disease.

However, the OECD estimates that the countries of the WHO European Region spend on average only 3\% of their health budgets on health promotion and disease prevention.

\section{Main Strategic Goals, Objectives and Content of Health 2020}

Health 2020 has two linked objectives:

- improving health for all and reducing health inequalities; and - improving leadership and participatory governance for health. In addition to these two objectives, the Health 2020 policy framework is based on four priority areas for policy action, which are interlinked, interdependent and mutually supportive:

- investing in health through a life-course approach and empowering people;

- tackling the Region's major health challenges of noncommunicable and communicable diseases;

- strengthening people-centred health systems, public health capacity and emergency preparedness, surveillance and response;

- creating resilient communities and supportive environments. Addressing all four priorities requires action across a range of cross-cutting issues. The new type of governance for health that is needed will be based on the social determinants of health, equity and sustainability, based on achieving global and societal goals through new interconnected forms of formal and informal governance and new strategic relationships and built around people's strong voice and involvement.

Governments achieve higher health impact when they link policies, investment and services and focus on reducing inequalities. They have a clear responsibility to develop intersectoral national strategies that combine planning and oversight together with goals and targets on key challenges such as the life course, strengthening health systems and public health and empowering people. Such intersectoral strategies, for example, use fiscal policies and regulation; focus on action in settings such as schools or workplaces; and promote secondary prevention, including risk assessment and screening. 
Mental health problems deserve a specific mention. These are a major cause of long-term stress and disability. About one fourth of the people in the European Region experience some type of mental health problem during their lives. Research is leading to a better understanding of the damaging association between mental health problems and social marginalization, unemployment, homelessness and alcohol and other substance abuse disorders. A particular challenge is to promote the early diagnosis of depression and prevent suicide by initiating community-based intervention programmes. This has been of particular significance during the recent economic crisis during which, for example, suicides increased by $17 \%$ in Greece and 13\% in Ireland (7). Evidence suggests that like other adverse health effects of the economic downturn, such increases can be significantly mitigated by welltargeted social protection and active labour market policies.

Health 2020 is fully consistent with WHO's General Programme of Work and other international developments and instruments. It supports the globally intensifying efforts to control noncommunicable diseases, such as the United Nations 2011 political declaration on noncommunicable diseases; the WHO Framework Convention on Tobacco Control; and the Global Strategy on Diet, Physical Activity and Health. Strong efforts also continue to be needed to combat communicable diseases, requiring the full implementation of the International Health Regulations, improving information exchange and joint surveillance and disease control activities.

In tackling the complex and interrelated determinants of today's diseases, in which policy decisions need to be taken under conditions of uncertain and imperfect knowledge, approaches based on rational linear thinking are inadequate. Knowledge derived from systems and complexity thinking is required to deal with situations in which the wider system effects of many interventions cannot be fully predicted. To accommodate these uncertainties, smaller-scale interventions that encourage learning and adaptation are proving increasingly important.

Health 2020 focuses on strengthening patient-centred health systems and their capacity to deliver high-quality care and improved outcomes. Health systems need to be financially viable and sustainable, fit for purpose and evidence-informed. This requires reorientation to give priority to disease prevention, integrated service delivery, continuity of care, continual quality improvement and support for self-care by patients, with care relocated as close to home as is safe and cost-effective. Providing universal access remains a commitment both of WHO globally and of Health 2020, alongside the commitment to primary health care as the cornerstone of health systems in the 21 st century. All these developments in health systems and public health require a more flexible, multi-skilled and team oriented workforce.

Health 2020 was supported by the development of a European Action Plan for Strengthening Public Health Capacities and Services, which was also approved by the WHO Regional Committee for Europe in 2012 as a key pillar of implementing Health 2020. The Action Plan focuses on improving public health services and infrastructure, including the public health aspects of health care services. The Action Plan proposes a set of 10 horizontal essential public health operations to become the unifying and guiding basis for European health authorities to monitor, evaluate and set up policies, strategies and actions for reforms and improving public health. Achieving better health outcomes requires substantially strength- ening public health functions and capacity; investing in public health institutional arrangements; making efforts to strengthen health protection, health promotion and disease prevention.

Building resilience is a key factor in protecting and promoting health and well-being at both the individual and community levels. Resilient communities have, or are able to develop, assets that allow them to respond proactively to new or adverse situations. They are also able to prepare for economic, social and environmental change and deal well with crisis and hardship.

Hazards in the environment are a major determinant of health, with many health conditions being linked to such factors as air pollution and the impact of climate change. Such factors interact with the social determinants of health. The benefits to health of a low-carbon economy and health co-benefits of environmental policies are being considered in the context of Rio +20 , the United Nations Conference on Sustainable Development.

\section{The Implementation Process and What is Next for Countries}

It is recognized that, in tackling health development, countries will engage with Health 2020 from different contexts and with different capabilities. At the same time, the policy framework is intended to be coherent and practical despite these different starting-points. Specific aims would include achieving strong political commitment to health and moving health up the policy agenda; adopting a health in all policies approach; strengthening the policy dialogue on health and its determinants; and building accountability for health outcomes.

Health 2020 provides evidence-informed solutions to all these challenges. To facilitate its work with countries and to support Health 2020, the WHO Regional Office for Europe is constructing a package of services and tools that will offer countries systematic support in tackling the core horizontal strategic issues of Health 2020 (Fig. 2 shows the nine package components) as well as programmatic links and entry points to more detailed aspects of the policy framework. For each of the package components, a limited menu of priority and high-net-gain services, guidance and tools will be provided. The package will be regularly updated to reflect learning from progress in countries and make available promising practices and expertise.

The starting-point for countries must be developing a national health policy, with its supporting strategies and plans. Based on a solid needs assessment, what is the country hoping to achieve in terms of equitable health improvement? What multisectoral policies and strategies will it use, for example for noncommunicable diseases? The Health 2020 package of tools and instruments is intended to help here. In terms of public health, analysing the European Action Plan for Strengthening Public Health Capacities and Services and its associated self-assessment tool will also give clear guidance. Health 2020 is not for academic study and dusty shelves; it is a guide for practical implementation.

Health impact assessment and economic evaluation are also valuable tools in assessing the potential impact of policies and can also be used to assess how policies affect equity, and both qualitative and quantitative health data can be used to assess how policies affect health.

Most promisingly, a number of countries are already developing overarching Health 2020 policies and supporting strategies 


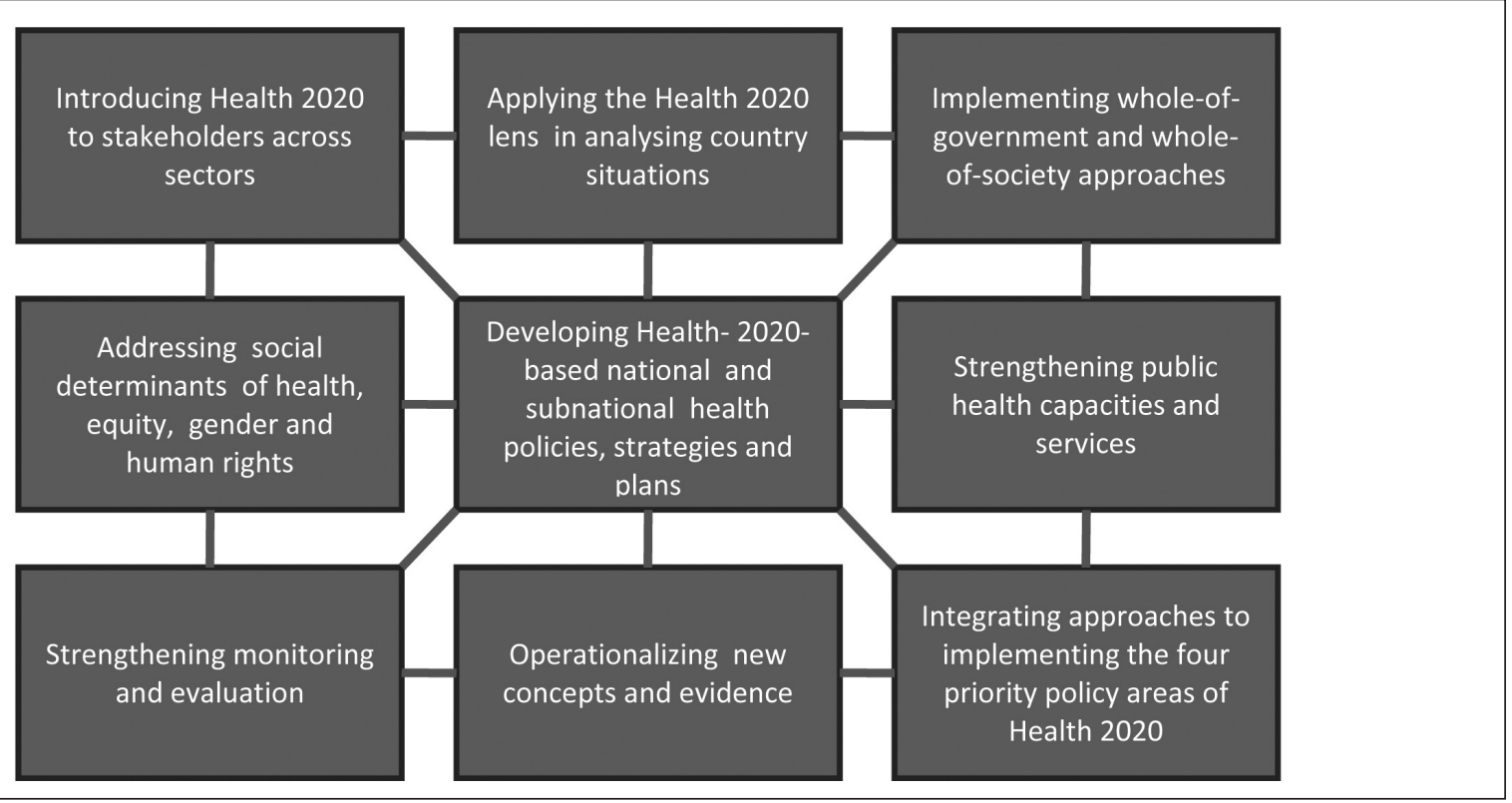

Fig. 2. The nine package components of Health 2020.

and plans aligned with the health policy framework. Others are taking forward specific elements of Health 2020 in accordance with Health 2020 values and principles. The WHO Regional Office for Europe is now taking a systematic approach to supporting countries in their Health 2020 implementation work during 2014-2015. As another initiative, the Regional Office will also support the development of new forms of networking among countries, institutions and people, including web-based collaboration.

The implementation of Health 2020 will require the active input of many organizations and entities interested in health development and public health across Europe. Working with the EU will provide a strong foundation, significant opportunities and additional benefits. Many other organizations and networks too numerous to mention individually must similarly be engaged. Although attitudes towards the private business sector vary, their ethical engagement can be a powerful contributor to achieving Health 2020.

The WHO European Healthy Cities Network is an example of an important network that can do much to facilitate the implementation of Health 2020. About $69 \%$ of the people in the European Region live in urban settings, and urban areas can provide great opportunities for individuals and families to prosper. Cities can be engines of economic prosperity and can promote health through enhanced access to services, culture and recreation. Nevertheless, cities can also concentrate poverty and ill health. Some circumstances of urban life, especially segregation and poverty, contribute to and reinforce such discrepancies, by imposing disproportionate exposure to health-adverse and socially undesirable patterns of response to economic and social deprivation.

Cities and their governments can influence people's health and well-being through various policies and interventions, including those addressing social exclusion and support; healthy and active living; safety and environmental issues; working conditions; preparedness to deal with the consequences of climate change; exposure to hazards and nuisances; healthy urban planning and design; and participatory and inclusive processes for citizens. The WHO European Healthy Cities Network provides many examples of good practice across the WHO European Region and will act as a strategic vehicle for implementing Health 2020 at the local level.

The WHO Regional Office for Europe will establish and maintain effective collaboration with all such partners and networks across the Region: engaging widely; helping to increase policy coherence; sharing health data sets; joining forces for surveillance; and contributing to shared policy platforms, assessment missions, workshops and individualized consultancy, as well as technical dialogues and case studies.

\section{Accountability and Targets}

Political commitment to this process of implementation is essential globally, regionally, nationally and subnationally. At the session of the WHO Regional Committee for Europe in 2013, countries adopted the following overarching or headline targets as shown below (8).

1. Reduce premature mortality in Europe by 2020.

2. Increase life expectancy in Europe.

3. Reduce inequities in Europe (social determinants of health target).

4. Enhance the well-being of the European population.

5. Universal coverage and the "right to health".

6. National targets or goals set by Member States.

\section{CONCLUSION}

Health improvement in today's world must reflect the wide and complex range of determinants and influences on health, and the multisectoral and multifaceted nature of policy responses and interventions. Health 2020 reflects this reality, seeking a step-change in priority and investment to be given to social determinants of health and to health promotion and disease prevention. Whole-ofgovernment and whole-of-society policies need to be developed to reflect the complexity of determinants of health in today's diverse and horizontally networked, information-based societies. 
Knowledge is sufficient to improve health and reduce inequities. The world envisaged by WHO is one in which gaps in health outcomes are narrowed; universal access to health care is achieved; countries have resilient health systems, based on primary health care, that can meet the expectations and needs of their people; internationally agreed health goals are reached; noncommunicable diseases are controlled; and countries cope with disease outbreaks and natural disasters.

Health 2020 can help achieve all these objectives. It is a powerful vehicle for collective action across the whole of the WHO European Region to seize new opportunities to enhance the health and well-being of present and future generations. As the WHO Director-General said in the foreword to the Health 2020 publication (9): "The framework crystallizes what we have learned about the role of health in recent years. Maximizing health through all stages of life is a fundamental right for all and not a privilege for a few. Good health is an asset and a source of economic and social stability. It is key to reducing poverty and contributes to and benefits from sustainable development". Accordingly, Health 2020 is a powerful vehicle for collective action across the whole of the WHO European Region to seize new opportunities to enhance the health and well-being of present and future generations.
2. Kickbusch I, Gleicher D. Governance for health in the 21st century. Copenhagen: WHO Regional Office for Europe; 2012.

3. Bertollini R, Brassart C, Galanaki C. Review of the commitments of WHO European Member States and the WHO Regional Office for Europe between 1990 and 2010. Analysis in the light of the Health 2020 strategy. Copenhagen: WHO Regional Office for Europe; 2012.

4. McQueen DV, Wismar M, Lin V, Jones CM, Davies M, editors. Intersectoral governance for health in all policies: structures, actions and experiences. Observatory studies series no. 26. Copenhagen: WHO Regional Office for Europe; 2012

5. World Health Organization. Health 2020: a European policy framework supporting action across government and society for health and wellbeing. Copenhagen: WHO Regional Office for Europe; 2012.

6. Health 2020: policy framework and strategy. In: World Health Organization. Health 2020: a European policy framework and strategy for the 21 st century. Copenhagen: WHO Regional Office for Europe; 2013. p. 25-182.

7. Stuckler D, Basu S, Suhrcke M, Coutts A, McKee M. Effects of the 2008 recession on health: a first look at European data. Lancet. $2011 \mathrm{Jul}$ 9;378(9786):124-5.

8. World Health Organization. Health 2020 targets, indicators and monitoring framework. Copenhagen: WHO Regional Office for Europe; 2013.

9. World Health Organization. Health 2020: a European policy framework and strategy for the 21 st century. Copenhagen: WHO Regional Office for Europe; 2013.

\section{REFERENCES}

1. Marmot M; UCL Institute of Health Equity. Review of social determinants and the health divide in the WHO European Region: final report. Copenhagen: WHO Regional Office for Europe; 2013. 